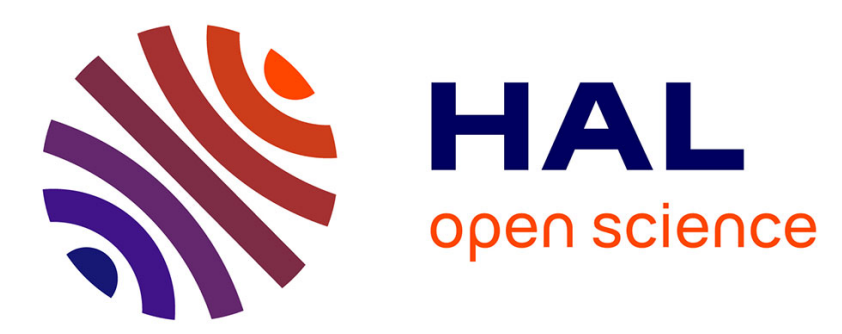

\title{
A High-Speed Photographic Study of the Rapid Deformation of Metal Annuli : Comparison of Theory with Experiment
}

\author{
S. Walley, P. Church, M. Furth, John Field
}

\section{- To cite this version:}

S. Walley, P. Church, M. Furth, John Field. A High-Speed Photographic Study of the Rapid Deformation of Metal Annuli: Comparison of Theory with Experiment. Journal de Physique IV Proceedings, 1997, 07 (C3), pp.C3-317-C3-322. 10.1051/jp4:1997356 • jpa-00255513

HAL Id: jpa-00255513

https://hal.science/jpa-00255513

Submitted on 1 Jan 1997

HAL is a multi-disciplinary open access archive for the deposit and dissemination of scientific research documents, whether they are published or not. The documents may come from teaching and research institutions in France or abroad, or from public or private research centers.
L'archive ouverte pluridisciplinaire HAL, est destinée au dépôt et à la diffusion de documents scientifiques de niveau recherche, publiés ou non, émanant des établissements d'enseignement et de recherche français ou étrangers, des laboratoires publics ou privés. 


\title{
A High-Speed Photographic Study of the Rapid Deformation of Metal Annuli: Comparison of Theory with Experiment
}

\author{
S.M. Walley, P.D. Church*, M. Furth* and J.E. Field \\ Cavendish Laboratory, Madingley Road, Cambridge CB3 OHE, U.K. \\ * DRA Fort Halstead, Sevenoaks, Kent TN14 7BP, U.K.
}

\begin{abstract}
Résumé : Pour vérifier le modèle de comportement d'un métal, il est important de déterminer comment il faut corriger les courbes contrainte-deformation obtenues en compression afin de tenir compte des effets de frottement. Dés erreurs graves viennent d'être découvertes dans les modèles analytiques standards utilisés pour déterminer les dites corrections dans les barres de Hopkinson. Dans le présent article nous proposons une nouvelle méthode pour déterminer le coefficient de frottement dans la compression axiale dynamique d'un anneau. La méthode utilise la modélisation numérique et la photographie utrarapide. Elle est validée en utilisant un acier à blindage.
\end{abstract}

\begin{abstract}
It is very important to know what friction correction to make to stress-strain curves obtained in compression so that constitutive models of metals can be accurately checked. However, it recently became apparent that standard analytical models commonly used to correc for friction in the split Hopkinson pressure bar have some serious errors. In this paper, we report a novel method of determining the friction coefficient for the case of axial compressive dynamic deformation of annuli. The method combines numerical modelling with high-speed photography and has been validated using Rolled Homogeneous Armour (RHA) steel.
\end{abstract}

\section{INTRODUCTION}

Friction between the specimen ends and the anvils has long been recognised as a problem in compression testing, both at low [1] and at high rates of deformation $[2,3]$. It has two major effects: (i) it generates a shear stress at the specimen/anvil interface and so changes the state of stress in the specimen from uniaxial to triaxial [4] which leads in turn to the measured stress being higher than the true yield stress of the material [5]; (ii) the specimen does not preserve its original geometry but 'barrels' [4]. And if such a specimen is cross-sectioned after deformation, it often shows an ' $\mathrm{X}$ '-shaped pattern of intense shear due to frictional locking of the surface producing truncated cones of non-deforming material which slide over the unconstrained material at the sides [4]. If the strain rates are high enough, substantial local temperature rises may occur in these shear zones, known as 'heat crosses' [6] or, more generally, adiabatic shear bands' [7]. Friction can also lead to cracking of the specimen e.g. [8].

Although friction has been studied for many years and the mechanisms that give rise to it are quite well-understood e.g. [9-12] it is not possible to predict its magnitude for any given pair of materials under specified conditions [13], though there have been a few recent attempts at doing so e.g. [14, 15]. To put it another way, constitutive equations have not yet been developed which describe friction and this is a major hindrance to the numerical modelling of contact problems [16]. The main problems are that the surfaces of two materials in contact (i) have different mechanical properties to the bulk due to surface oxide layers, absorbed dirt or lubricants, (ii) are rough, and (iii) change with time during the deformation [17], even melting if the sliding speed is high enough $[18,19]$.

Most studies of friction have been concerned with sliding, but there is also a considerable literature on its effects in 'upset forging' due to the importance of this technique in the forming of materials into desired shapes e.g. [20]. The standard test for measuring friction in the upset forging geometry is to deform an annulus of the test material [21]. If the ratio of the inner to outer diameter remains constant then the lubrication conditions are perfect (zero friction). However, this has only been achieved for low strength materials such as polymers [22], and even then the lubrication is found to break down after a certain strain is exceeded [23]. No combination of surface preparation and lubrication system has been found which reduces friction to zero for metals in this geometry [24], though it can be reduced to low values (3-4\% of the shear yield strength at high rates of deformation [3]).

The standard ring test involves deforming the annulus to a certain strain, removing it from the apparatus and measuring the change in the radius of the hole and the change in thickness of the specimen. 
This measurement is then compared with a set of theoretical curves to read off a value for the friction e.g. $[25,26]$. There are several assumptions made in this procedure: (i) the specimen dimensions did not change between the time the deformation stopped and the measurement was made. This is probahly reasonable for metals but certainly not for polymers [23]). (ii) The friction remained constant during the deformation. This is probably reasonable for small strains but not for large plastic deformation as 'foldover' occurs in which material from the sides ends up on the top surface [27]; see also figure 1). Also the lubricant can be squeezed out during the deformation. (iii) The theory is true.

It is this third assumption that we set out to check in the work reported here.

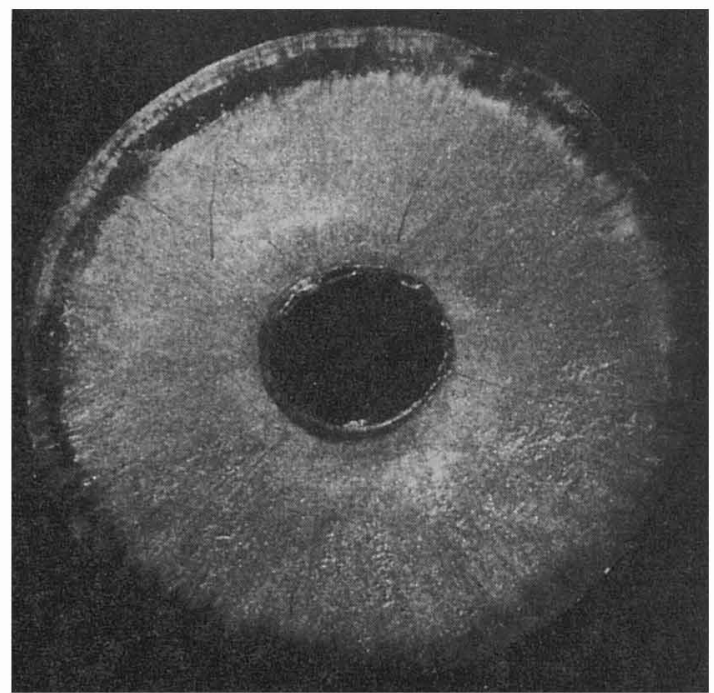

$2 \mathrm{~mm}$

a)

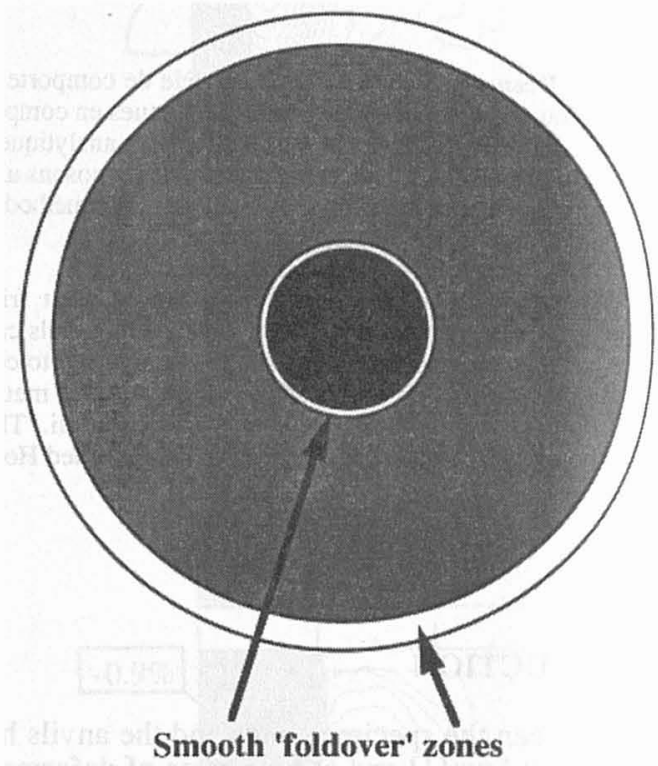

b)

Figure 1: (a) Photo of deformed annulus of Rolled Homogeneous Armour (RHA) lubricated by $\mathrm{MoS}_{2}$. Original dimensions: $\mathrm{OD}=5.00 \mathrm{~mm}, \mathrm{ID}=2.5 \mathrm{~mm}, \mathrm{t}=0.99 \mathrm{~mm}$. (b) Schematic drawing of fig. 1(a) showing the 'foldover' $z o n e s$.

\section{EXPERIMENTAL METHOD}

Ideally we wanted to be able to follow the deformation of metal annuli at strain rates typical of split Hopkinson bar testing $\left(10^{3}-10^{4} \mathrm{~s}^{-1}\right)$ as this places greater constraints on any potential model of friction than just measuring recovered deformed annuli. We decided it was not practicable to construct a Hopkinson bar out of glass, but strain rates of this order of magnitude could be achieved in our transparent glass anvil dropweight $(5.5 \mathrm{~kg}$ mass) apparatus $[23,28]$. Although the manner of loading is different, any differences between the dropweight and the Hopkinson bar would be detected in the modelling.

We studied annuli made from three different metals: OFHC XM copper with a $15 \mu \mathrm{m}$ grain size. rolled homogeneous armour (RHA) (Vickers hardness of 300), and EN24T steel (Vickers hardness of 250). Each was deformed under seven different lubrication conditions, namely (i) unlubricated, (ii) lubricated by one of three solid lubricants: molybdenum disulphide $\left(\mathrm{MoS}_{2}\right.$, colloidal graphite or boron nitride $(\mathrm{BN})$ ). The unlubricated tests were performed with the anvils 'as-received' (toughened float glass: no detectable roughness). The lubricated tests were performed with the anvils in one of two surface conditions: (i) as-received and (ii) polished to a $3 \mu \mathrm{m}$ diamond finish (as recommended by Gorham [3]). The three lubricants were chosen as being those most suitable for the three temperature regimes of interest [24]: $\mathrm{MoS}_{2}$ for cryogenic temperatures, graphite for room temperature up to about $200^{\circ} \mathrm{C}$, and $\mathrm{BN}$ for high temperatures (up to about $1200{ }^{\circ} \mathrm{C} ;[29]$ ). As the intention of this initial study was to prove the technique, we studied these lubricants at room temperature alone as our glass anvil dropweight apparatuls is at present only set up to operate in the lower part of this temperature range $\left(-196^{\circ} \mathrm{C}\right.$ to $\left.+100^{\circ} \mathrm{C}\right)$.

An example of the experimental data used to check the model is given in figure 2 . The sequence presented is not the same as the one that was modelled, because although measurements can be made from sequences obtained using roughened and lubricated anvils, the picture quality is of course poorer. 


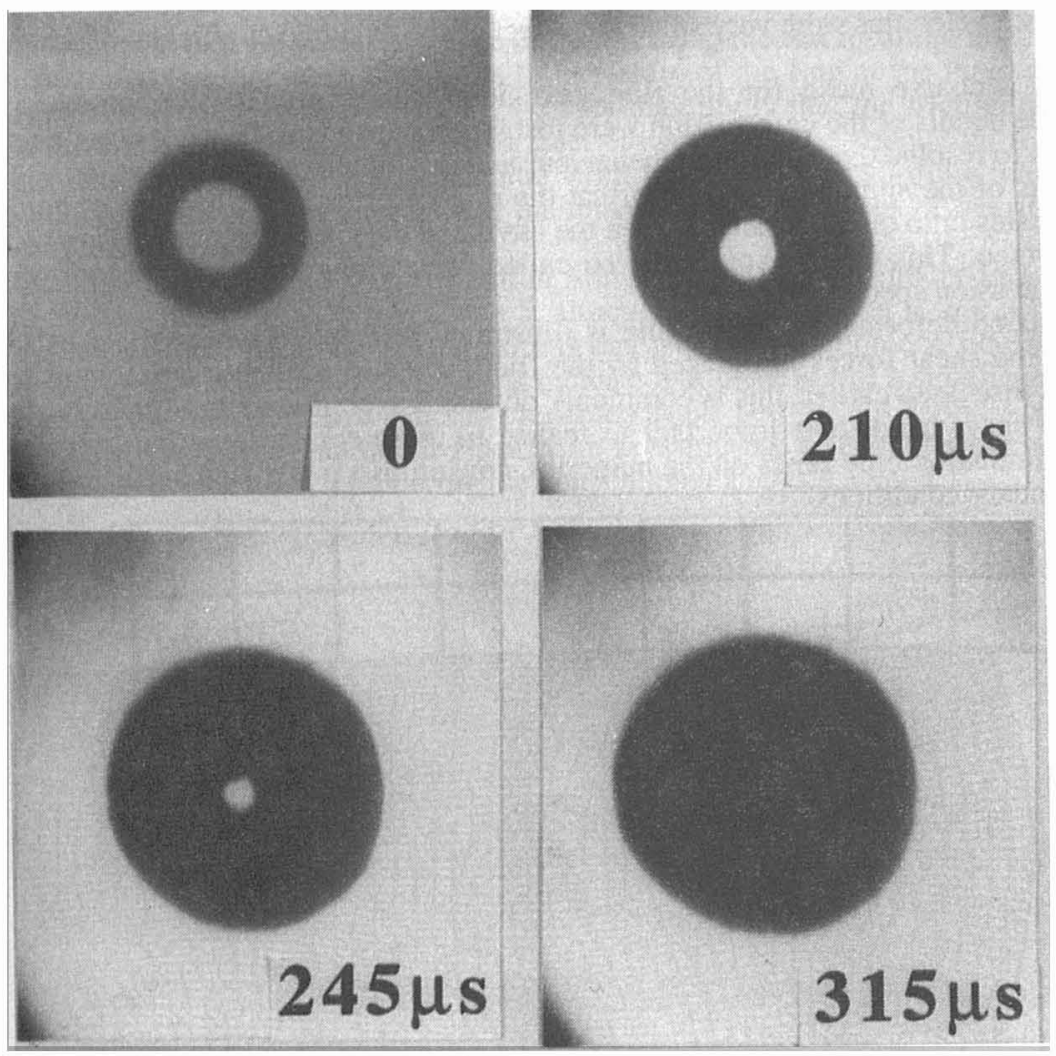

Figure 2: Selected frames from a high-speed photographic sequence of the rapid deformation of an unlubricated copper annulus deforming between smooth anvils. Original dimensions of the annulus: $\mathrm{OD}=5.00 \mathrm{~mm}, \mathrm{ID}=2.4 \mathrm{~mm}, \mathrm{t}=0.87 \mathrm{~mm}$.

\section{NUMERICAL MODELLING}

The aim of the numerical modelling was to provide a direct comparison between experiment and theory for the ring deformation and to gain insight into the deformation mechanisms exhibited. The numerical modelling was performed using the public domain Lagrange hydrocode DYNA2D obtained from the Lawrence Livermore laboratories and developed within DERA featuring contact algorithms or slidelines with Coulomb friction. The ring tests on RHA were chosen for a direct comparison with the experimental tests since a full constitutive model based on a modified form of the Armstrong-Zerilli model [30] has been developed for this material [31]. The model for the RHA is as follows:-

$$
\sigma=\left(C_{1}+C_{5} \varepsilon^{n}\right) \frac{\mu_{T}}{\mu_{293}}+C_{2} \exp \left[\left(-C_{3}+C_{4} \operatorname{In} \dot{\varepsilon}\right) T\right]
$$

where $C_{1}=710 \mathrm{MPa}, C_{2}=575 \mathrm{MPa}, C_{3}=0.0048, C_{4}=0.00032, C_{5}=567 \mathrm{MPa}, n=0.41, \mu_{T}$ is the shear modulus at temperature $T$, and $\mu_{293}$ is the shear modulus at room temperature.

Since the rings always closed up in the experiments, even with lubrication, friction was evidently always present. Thus the issue was to determine a coefficient of friction along the interface which gave good agreement between the experiment and simulation in terms of the inner and outer surface displacements. The friction coefficient $\mu$ at the interfaces between the bars and the specimen is defined as:-

$$
\mu=\mu_{k}+\left(\mu_{s}+\mu_{k}\right) \exp (-\beta v)
$$

where $\mu_{k}$ is the dynamic coefficient of friction, $\mu_{s}$ is the static coefficient of friction, $\nu$ is the relative interface velocity, and $\beta$ is a constant. The dynamic coefficient $\mu_{k}$ and the constant $\beta$ were chosen so that the overall coefficient of friction $\mu$ was always a constant value of 0.1 throughout the simulation. Also 
since the interface velocities were very small the effect of the dynamic coefficient of friction was generill ly negligible.

Although a coarse mesh for the ring gave identical results for the inner and outer surface displacement the details of the deformation were resolution dependent, hence it was decided to use a finer mesh to attempt to resolve the localisation behaviour and deformation mechanisms.

The results of the simulations confirm that the ring deforms in a 'flowing' or foldover motion (so that material rotates onto the interface between the anvil and the specimen) rather than by a sliding motion along the interface. This could explain the so called 'machining rings' which are often observed on recovered compression specimens.

The simulated deformation of the ring is illustrated in figure 3 where the mesh is attempting to localise due to the shear forces introduced by the friction which produces a diamond shaped pattern of localisation. As discussed earlier, this is commonly observed experimentally [4] and is often the precursor of an adiabatic shear band. It is important to realise in these simulations that there is no localisation criterion. The simulation only relies on the numerics, constitutive model and sufficient mesh resolution to resolve the boundary conditions.

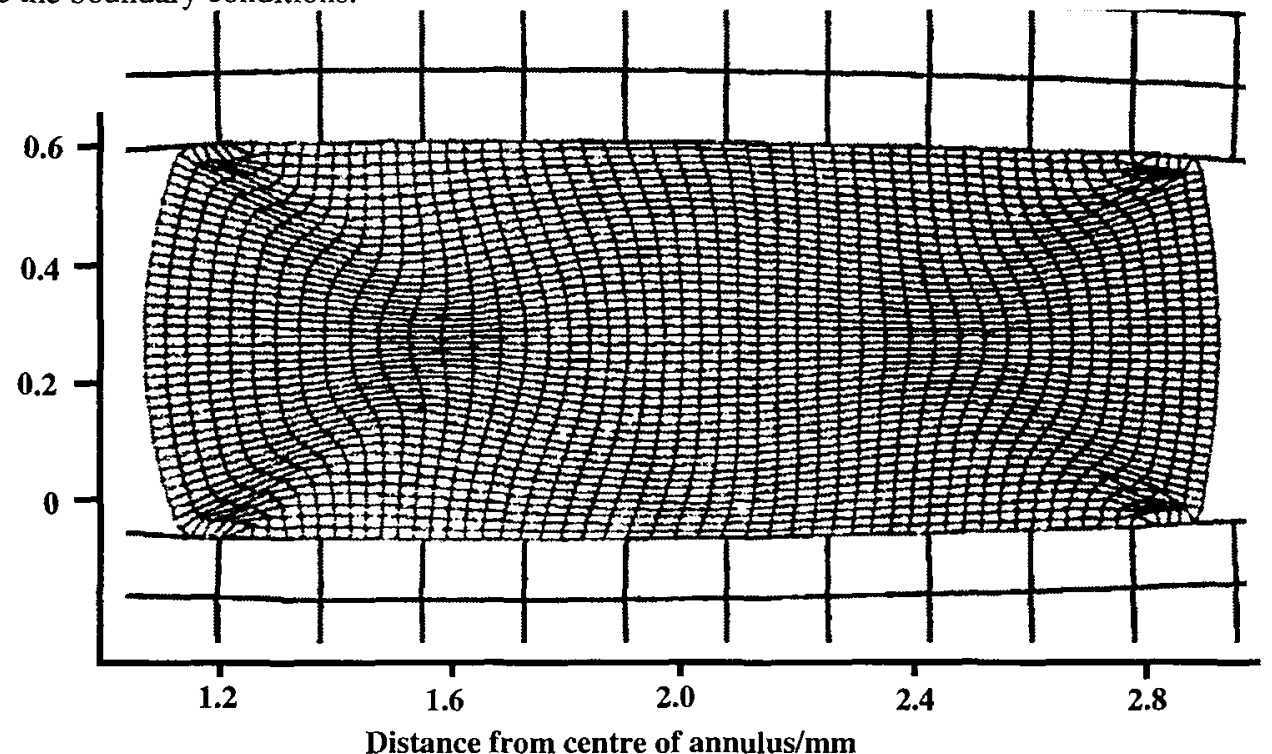

Figure 3: Mesh localisation after $100 \mu$ s in simulation of the dynamic deformation of an RHA annulus.

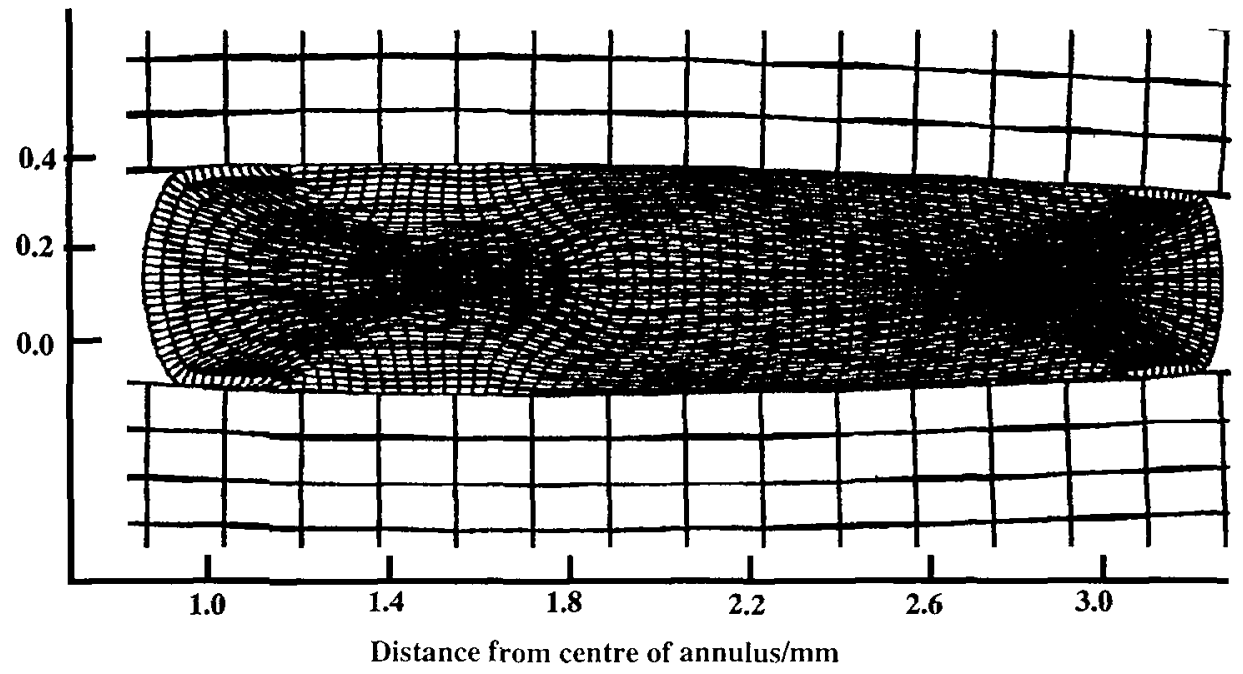

Figure 4: Simulation after; $160 \mu$ s showing indentation of glass anvils and different inner and outer radii. 
An additional effect is that the glass anvil also deforms during the test resulting in a load distribution on the specimen such that the thickness and radius of curvature of the ring at the inner and outer radius become markedly different at large strains (figure 4). This may imply that the friction conditions at the inner surface are different to those at the outer surface. However, in the simulation reported here the friction coefficient was constant. Future experimental work will involve performing interrupted tests to determine the thicknesses and radii of curvature at the inner and outer surfaces of the ring specimen for comparison with simulation.

The numerical simulation agrees well (to within 5\%) with the experimentally measured inner and outer surface ring displacements as shown in figure 5, although the comparison is less good at later times for the inner ring displacement. An interesting feature is that when the friction coefficient is increased to 0.2 the results are not greatly different. These results indicate that there is still a significant friction effect at room temperature even when lubricants generally regarded as the best for this application are used. This could have implications in conventional split Hopkinson pressure bar tests as the stress system in this nominally uniaxial test is in fact triaxial rendering the conventional analysis invalid.

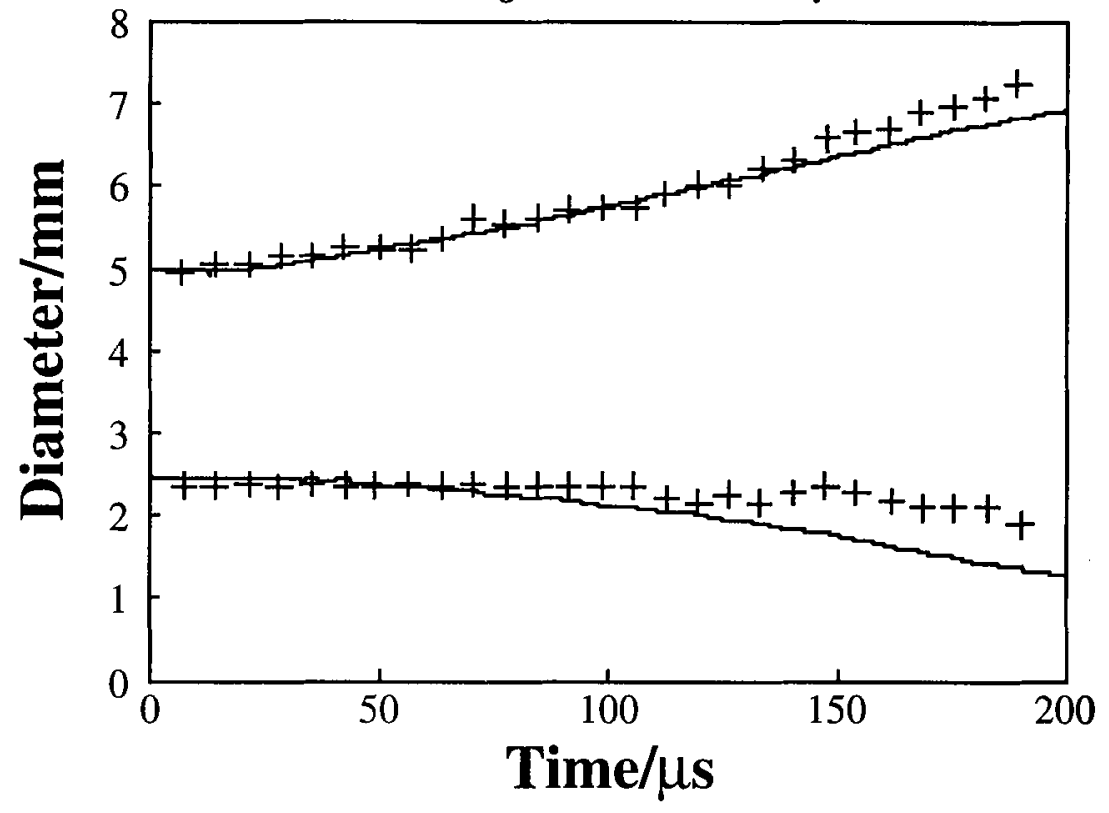

Figure 5: Comparison of simulation (solid line) with experiment (crosses) for the dynamic deformation of an annulus of RHA deformed between smooth glass anvils and lubricated by molybdenum disulphide. Upper line is the outer diameter; lower line is the inner diameter. Original thickness $=0.99 \mathrm{~mm}$. Measurement error $=0.1 \mathrm{~mm}$. Friction coefficient in the simulation was 0.1 .

\section{CONCLUSIONS}

(i) Simulations using a friction coefficient of 0.1 are in good agreement with the experimental measurements of the inner and outer ring displacements for an annulus of RHA lubricated by $\mathrm{MoS}_{2}$ dynamically deformed between smooth glass anvils in a drop-weight machine.

(ii) The simulations predict a difference in the thickness and radius of curvature at the inner and outer ring surfaces due to the deformation mechanisms present in the test.

(iii) The simulations are capable of resolving the shear localisation behaviour of the material induced by the friction at the interfaces.

(iv). All the lubricants tested exhibit a significant friction in this experimental configuration.

다 Crown copyright 1997

\section{Acknowledgements}

B. Goldthorpe is thanked for his encouragement and advice, and J. Balzer for his assistance with the highspeed photography. The research was supported by a grant from DRA (Fort Halstead). 


\section{References}

1. Hartley P., Sturgess C.E.N. \& Rowe G.W., Int. J. Mech. Sci. 22 (1980) 743-753

2. Klepaczko J. \& Malinowski Z., in "High Velocity Deformation of Solids" ed. K. Kawata \& J

Shioiri, publ. Springer-Verlag, Berlin, 1978, pp. 403-416.

3. Gorham D.A., Pope P.H. \& Cox O., Inst. Phys. Conf. Series 70 (1984) 151-158

4. Mescall J., Papirno R. \& McLaughlin J., in "Compression Testing of Homogeneous Materials and Composites", ASTM STP 808, ed. R. Chait \& R. Papirno, publ. American Society for Testing and Materials, Philadelphia, 1983, pp. 7-23.

5. Schey J.A., Venner T.R. \& Takomana S.L., J. Mech. Work. Technol. 6 (1982) 23-33

6. Johnson W., Baraya G.L. \& Slater R.A.C., Int. J. Mech. Sci. 6 (1964) 409-414

7. Bai Y.L. \& Dodd B., "Adiabatic Shear Localization: Occurrence, Theories and Applications" publ. Pergamon, Oxford, 1992

8. Jenner A., Bai Y. \& Dodd B., J. Strain Analysis 16 (1981) 159-164

9. Bowden F.P. \& Tabor D., "The Friction and Lubrication of Solids. Part I" publ. Oxford Universill" Press, Oxford, 1950

10. Bowden F.P. \& Tabor D., "The Friction and Lubrication of Solids. Part II" publ. Oxford University Press, Oxford, 1964

11. Singer I.L. \& Pollock H.M., eds, "Fundamentals of Friction: Macroscopic and Microscopic

Processes" publ. Kluwer Academic, Dordrecht, The Netherlands, 1992

12. Krim J., Scientific American 275(4) (October 1996) 74-80

13. Feynman R.P., Leighton R.B. \& Sands M., "The Feynman Lectures on Physics. Vol. 1" publ. Addison-Wesley, Reading, Massachusetts, 1963, chapter 12, pp. 3-5.

14. Miyoshi K. \& Buckley D.H., ASLE Trans. 27 (1984) 15-23

15. Carter W.T. Jr., Trans. ASME: J. Engng Mater. Technol. 116 (1994) 8-13

16. Oden J.T. \& Martins J.A.C., Comput. Meth. Appl. Mech. Engng 52 (1985) 527-634

17. Archard J.F., Wear 2 (1958) 438-455

18. Bowden F.P. \& Freitag E.H., Proc. R. Soc, Lond. A248 (1958) 350-367

19. Montgomery R.S., ASLE Trans. 28 (1985) 117-122

20. Dieter G.E., in "Metals Handbook, 9th Edition, Vol. 8" publ. American Society of Metals, Metils Park, Ohio, 1985, pp. 571-597.

21. Martorell I.A., in "Compression Testing of Homogeneous Materials and Composites", ASTM STP 808, ed. R. Chait \& R. Papirno, publ. American Society for Testing and Materials, Philadelphia, 1983, pp. 78-94.

22. Briscoe B.J. \& Nosker R.W., Wear 95 (1984) 241-262

23. Walley S.M., Field J.E., Pope P.H. \& Safford N.A., Phil. Trans. R. Soc. Lond. A328 (1989) 1-33

24. Lovato M.L. \& Stout M.G., Metall. Trans. A 23 (1992) 935-951

25. Avitzur B., Israel J. Technol. 2 (1964) 295-304

26. de Pierre V. \& Gurney F., Trans. ASME: J. Lub. Technol. 94 (1974) 482-488

27. Pearsall G.W. \& Backofen W.A., Trans. ASME: J. Engng Indust. 85 (1963) 68-76

28. Heavens S.N. \& Field J.E., Proc. R. Soc. Lond. A338 (1974) 77-93

29. Lansdown A.R., "High Temperature Lubrication" publ. Mechanical Engineering Publications Ltd., London, 1994

30. Zerilli F.J. \& Armstrong R.W., J. Appl. Phys. 61 (1987) 1816-1825

31. Goldthorpe B.D., Butler A.L. \& Church P., J. Phys. IV France 4 Colloq. C8 (EURODYMAT 94) (1994) 471-476 